\title{
Role of Transcerebellar Diameter Measurement with Ultrasonography in Evaluation of Gestational age in Normal and Growth Restricted Fetuses
}

\author{
Amandeep Singh ${ }^{1}, \mathrm{CL}$ Thukral ${ }^{2}$, Jasmeet Singh ${ }^{3}$, Kamlesh Gupta ${ }^{4}$, Sangeeta Pahwa ${ }^{5}$ \\ ${ }^{1}$ Associate Professor, SGRD Institute of Medical Sciences and Research, Amritsar, India. ${ }^{2}$ Professor, SGRD Institute of Medical Sciences and Research, Amritsar, \\ India, ${ }^{3}$ Resident, SGRD Institute Of Medical Sciences And Research, Amritsar, India, ${ }^{4}$ Professor \& Head, SGRD Institute Of Medical Sciences And Research, \\ Amritsar, India, ${ }^{5}$ Professor, Obstetrics and Gynaecology, SGRD Institute Of Medical Sciences And Research, Amritsar, India.
}

\section{Abstract}

Background: To study the usefulness of transcerebellar diameter measurement ultrasonographically for the detection of gestational age in normal and intra uterine growth restricted fetuses and compare the gestation age determined by transcerebellar diameter with that determined by other parameters i.e. biparietal diameter, head circumference, abdominal circumference and femur length. Subjects and Methods: A prospective study with ultrasonographic evaluation of five hundred antenatal patients in gestational age of 14-39 weeks. The transcerebellar diameter was measured and the corresponding gestational age determined. The gestational age was also determined with other parameters such as biparietal diameter, head circumference, abdominal circumference and femur length. Transcerebellar circumference to abdominal circumference ratio was calculated. Results: There is statistically significant relationship between Transcerebellar diameter and gestational age in normal and intra uterine growth retarded pregnancies. Transcerebellar diameter showed good correlation with gestational age (correlation coefficient $=0.979$ ) in case of normal pregnancies and ( correlation coefficient $=0.942$ ) in cases of intra uterine growth retarded pregnancies Gestational age estimated by transverse cerebellar diameter measurements correlated well with gestational age estimated by biparietal diameter, head circumference, abdominal circumference and femur length. Transcerebellar circumference to abdominal circumference ratio remained fairly constant. Conclusion: Transcerebellar diameter can be used as a independent growth parameter to predict the gestational age in normal and in intrauterine growth retarded pregnancies cases. Transcerebellar diameter to abdominal circumference ratio is fairly constant throughout gestation and thus it is a useful gestational age independent parameter.

Keywords: Transverse cerebellar Diameter, Gestational age, Ultrasound, Fetus.

Corresponding Author: Dr. Amandeep Singh, Associate Professor, Department of Radiodiagnosis, SGRD Institute of Medical Sciences and Research, Amritsar, India.

Received: December 2018

Accepted: December 2018

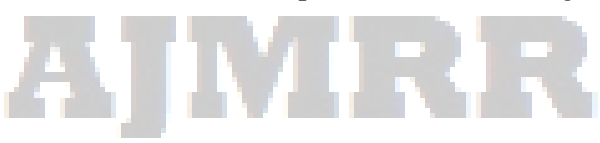

\section{Introduction}

Sonographic prediction of gestational age (GA) based on fetal parameters is the cornerstone in modern obstetrics and plays a crucial role in the management of pregnancies. The methods used to estimate gestational age(GA) and to predict the expected date of delivery are: ${ }^{[1]}$ Menstrual history, Clinical examination Perception of fetal movement, The Nagele's rule. The obstetrician calculates the EDD as 280 days or 40 weeks from the first day of the LMP. Among the various clinical criteria, Last Menstural Period (LMP) preceded by normal cycle, is known to correlate best with the gestational age. LMP may be unreliable or misleading because of oligomenorrhea, abnormal bleeding events, becoming pregnant in the first ovulatory cycle after a recent delivery and use of oral contraceptives or if ovulating very early (< day 11 ) or very late (>day 21 ) in the menstrual cycle.

The use of obstetric ultrasonography is related to the uncertainity regarding the gestational age and is presently the most effective way in dating of pregnancy. ${ }^{[2]}$ The commonly used ultrasound biometric parameters include the biparietal diameter(BPD), head circumference (HC), abdominal circumference(AC) and Femur length(FL). ${ }^{[3-5]}$ However the variability in assessing the gestational age with these parameters goes on increasing with increasing gestational age. $^{[6-9]}$

Transverse cerebellar diameter (TCD) measurement is emerging as a new parameter and has been proposed to be more accurate in estimation of gestational age .10 Also it has emerged as a useful parameter in growth restricted fetuses. ${ }^{[10]}$

The aim of this study is to evaluate the usefulness of transverse cerebellar diameter measurement ultrasonographically for the detection of gestational age in normal and intra uterine growth restricted fetuses and to compare the gestation age determined by transcerebellar diameter with gestational age determined by other parameters i.e. biparietal diameter, head circumference, abdominal circumference and femur length 


\section{Singh et al; Evaluation of Gestatianal age}

\section{Subjects and Methods}

This was a prospective study which included 500 antenatal women between 14 to 39 weeks, who had regular periods and are sure about their last menstrual period or have first trimester ultrasound confirmation of gestational age by means of crown rump length measurement and others included those who were clinically suspected intrauterine growth retardation. Cases were excluded if women had multiple gestation, women not sure of its last menstrual date or in case of any fetal malformation. Out of 500 cases, 76 were IUGR fetuses. The patients written consent to participate in this study has been obtained.

All the measurements were made by scanning the cases using GE VOLUSON E8 system using 3.5 Mhz transducer

\section{Technique of Measurement of Transverse Cerebellar Diameter-}

The measurement of TCD was obtained by the technique described by McLeasy et al (1984) and Goldstein et al (1987), in which the usual thalamic plane used for BPD is obtained, the transducer is then rotated about 300 below the thalamic plane to see the cerebellum. ${ }^{[1]}$ TCD is now measured and TCD/AC ratio is calculated. In all cases cerebellum was seen as two lobules on either side of midline in the posterior cranial fossa as shown in [Figure 1].

\section{Results}

In this study 500 cases were studied out of which 424 were normal pregnancies and 76 were IUGR pregnancies. For both the groups mean age and range of deviation were calculated using student $t$ test and $p$ values were estimated. The $\mathrm{p}$ value was found out to be 0.697 which indicates that there is no statistically significant difference between the age distributions of two groups.

Among the 500 normal pregnancies 236 were primigravida, 133 were gravida 2, 32 were gravida 3,21 were gravida 4 and 2 were gravida 5. Among the IUGR pregnant women 45 were primigravida, 21 were gravida 2, 6 were gravida 3 , 4 were gravida 4.

Comparison was done between the two groups with regards to parity using Chi Square test. The $\mathrm{p}$ value was found to be 0.936 which indicates that there is no stastically significant difference between the parity distributions of two groups [Figure 2].

For the 424 normal pregnancy patients all the parameters i.e TCD,BPD,HC,AC and FL were measured ultrasonographically in millimeters. Regression analysis was used to find out the correlation between TCD and each of the other parameters. Correlation coefficient (R) and $p$ values were calculated. Good correlation was found between TCD and other parameters ( $p$ value $<0.001$ ) [Table 1].

For the 424 normal pregnancy patients each parameter i.e TCD,BPD,HC,AC and FL was correlated with gestational age (GA) using regression analysis. The analysis showed of all the parameters TCD shows best correlation with gestational age [Table 2]. By using the ultrasonographically derived data, scatter diagram was devised showing linear correlation of TCD with gestational age as shown in [Figure 3].

Table 1: Table showing correlation of TCD with BPD,HC, AC,FL in normal pregnancies.

\begin{tabular}{|c|c|c|}
\hline $\begin{array}{c}\text { Parameters } \\
\text { Compared }\end{array}$ & $\begin{array}{c}\text { Correlation } \\
\text { Coefficent }(\mathbf{R})\end{array}$ & P Value \\
\hline TCD VS BPD & 0.984 & $<0.001$ \\
\hline TCD VS HC & 0.976 & $<0.001$ \\
\hline TCD VS AC & 0.977 & $<0.001$ \\
\hline TCD VS FL & 0.983 & $<0.001$ \\
\hline
\end{tabular}

Table 2: Table showing correlation of GA with BPD,HC,AC

AND FL and TCD in normal pregnancies

\begin{tabular}{|c|c|c|}
\hline Parameters & R & P Value \\
\hline GA VS BPD & 0.975 & $<0.001$ \\
\hline GA VS HC & 0.968 & $<0.001$ \\
\hline GA VS AC & 0.973 & $<0.001$ \\
\hline GA VS FL & 0.975 & $<0.001$ \\
\hline GA VS TCD & 0.979 & $<0.001$ \\
\hline
\end{tabular}

Table 3: Normogram showing mean $\operatorname{TCD}(\mathrm{mm})$ measurements at 5th, 50th and 95th percentile for the corresponding gestational age

\begin{tabular}{|c|c|c|c|}
\hline GA & 5th Percentile & 50th Percentile & 95th Percentile \\
\hline 15th Week & 1.47 & 1.60 & 7.64 \\
\hline 16th Week & 1.54 & 1.56 & 4.92 \\
\hline 17th Week & 1.60 & 1.78 & 4.80 \\
\hline 18th Week & 1.68 & 1.71 & 1.84 \\
\hline 19th Week & 1.86 & 1.94 & 2.18 \\
\hline 20th Week & 1.59 & 2.06 & 2.43 \\
\hline 21th Week & 1.97 & 2.19 & 4.59 \\
\hline 22nd Week & 1.95 & 2.29 & 2.48 \\
\hline 23rd Week & 2.24 & 2.47 & 2.61 \\
\hline 24th Week & 1.85 & 2.64 & 3.76 \\
\hline 25th Week & 2.10 & 2.72 & 4.40 \\
\hline 26th Week & 2.35 & 2.96 & 4.40 \\
\hline 27th Week & 2.43 & 3.14 & 3.39 \\
\hline 28th Week & 2.87 & 3.38 & 3.83 \\
\hline 29th Week & 2.60 & 3.51 & 4.21 \\
\hline 30th Week & 3.36 & 3.68 & 4.42 \\
\hline 31th Week & 3.34 & 3.79 & 4.33 \\
\hline 32nd Week & 2.88 & 3.98 & 2.80 \\
\hline 33rd Week & 3.91 & 4.19 & 4.74 \\
\hline 34th Week & 2.19 & 4.47 & 4.96 \\
\hline 35th Week & 3.02 & 4.60 & 5.05 \\
\hline 36th Week & 2.63 & 4.8 & 5.18 \\
\hline 37th Week & 2.35 & 5.01 & 5.17 \\
\hline 38th Week & 4.78 & 5.37 & 5.49 \\
\hline 39th Week & 4.86 & 5.54 & 5.66 \\
\hline
\end{tabular}

Table 4: Table showing correlation of $\mathrm{GA}$ with $\mathrm{BPD}, \mathrm{HC}, \mathrm{AC}$ AND FL and TCD in IUGR pregnancies

\begin{tabular}{|c|c|c|}
\hline Parameters & R & P Value \\
\hline GA VS BPD & 0.879 & $<0.001$ \\
\hline GA VS HC & 0.866 & $<0.001$ \\
\hline GA VS AC & 0.845 & $<0.001$ \\
\hline GA VS FL & 0.862 & $<0.001$ \\
\hline GA VS TCD & 0.942 & $<0.001$ \\
\hline
\end{tabular}

The normogram was devised for TCD in case of normal pregnancies using ultrasonographically derived data. The normogram show mean measurements in millimeter $(\mathrm{mm})$ at 5th, 50th and 95th percentile for the corresponding gestational age. [Table 3]. 

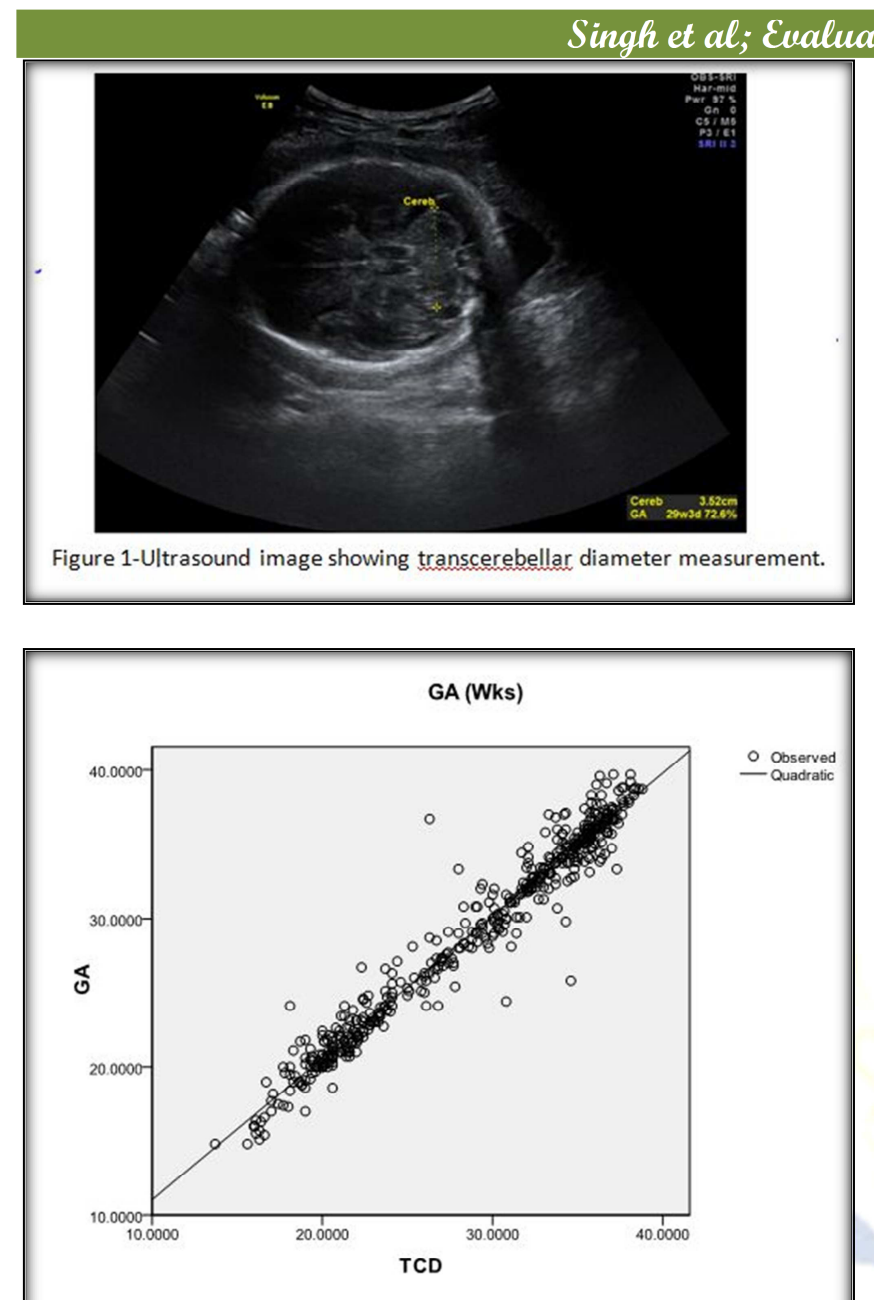

Fig. 3 : Scatter diagram showing correlation between GA and TCD.

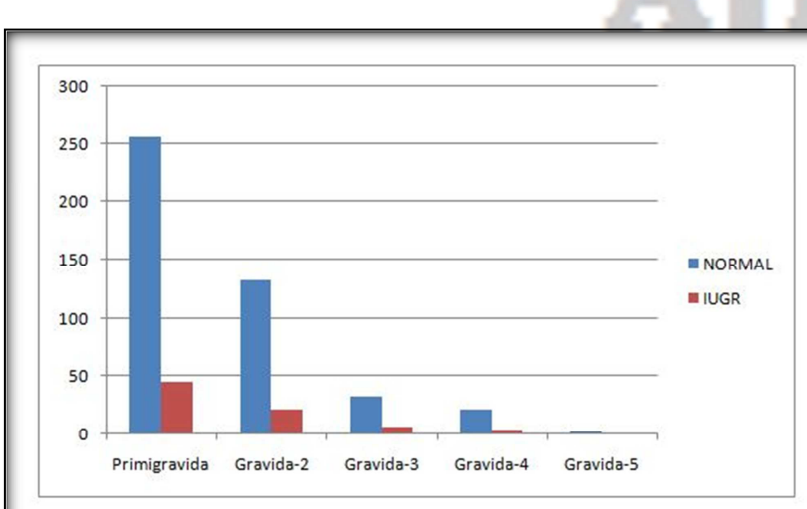

Figure 2: Bar diagram showing parity distribution of normal and IUGR pregnancy patients

In IUGR pregnancy cases each parameter-BPD,HC,AC,FL and TCD was correlated with gestational age using regression analysis. Of all parameters TCD showed best correlation with gestational age $(\mathrm{R}=0.942)$. The correlation was comparatively less strong between gestational age and other parameters [Table 4].

Also for all IUGR pregnancies the BPD,HC.AC,FL and TCD measurements were compared with normograms derived from normal pregnancies. Number of patients with
$\mathrm{BPD}, \mathrm{HC}, \mathrm{FL}, \mathrm{AC}$ and TCD values below 5th percentile values were recorded. It was seen that 20 cases were below the fifth percentile for AC and FL, 21 cases were below the fifth percentile for BPD and 29 cases were below the fifth percentile for FL. In 72 cases out of 76 the TCD values were within normal range. Only in 4 cases the TCD values were below the 5 th percentile. The difference in number of cases below the 5 th percentile for BPD,HC,AC,FL and TCD was statistically significant( $p$ value $<0.001$ ).

In this study the mean $\mathrm{TCD} / \mathrm{AC}$ ratio in normal pregnancy was found to be $0.1529 \pm 0.07$ (SD) which remained fairly constant throughout pregnancy and thus it is a useful gestational age independent parameter. The mean TCD/AC ratio in IUGR pregnancies was found to be $0.1711+-0.02$ (SD).

\section{Discussion}

Identification of aberrant growth as well as growth disturbances across the spectrum of GA in both healthy fetuses and those with genetic abnormalities will be helpful for optimal fetal surveillance. The biometric parameters used for gestational age assessment are BPD, HC, AC and FL.2,3,4. However each of these parameters have their own limitation. TCD serves as a unique parameter for estimation of gestational age and is a standard against which deviation in other parameters may be compared. ${ }^{[13]}$

The cerebellum, the largest part of the hind brain, is surrounded laterally by the dense petrous ridges and inferiorly by the occipital bone, which is aligned perpendicular to the plane of maximum extrinsic compression. Thus, the cerebellum and posterior fossa should theoretically be able to withstand deformation by extrinsic pressure better than the parietal bones.[14]

In this study 500 pregnant patients with known LMP were studied out of which 424 were normal pregnancies and 76 were IUGR pregnancies. There was no statistically significant difference between two groups with regards to age and parity ( $p$ values were $>0.05$ ).

In all these patients, ultrasonographic parameters like $\mathrm{BPD}, \mathrm{HC}, \mathrm{AC}, \mathrm{FL}$ and TCD were measured ultrasonographically and gestational age was correlated. Also attempt was made to correlate TCD with other parameters. Normogram was established for the mean TCD values at 5th, 50th and 95th percentiles for the corresponding gestational age. In case LMP is not known this normogram can be used for assessing the fetal gestational age and to asses any deviation from normal growth. Present study showed linear relation of transverse cerebellar diameter with gestational age which makes present study highly significant and proved that transverse cerebellar diameter may serve as a reliable indicator of gestational age, and fetal growth.

Goldstein et al, ${ }^{[15]}$ prospectively studied ultrasonography of 371 normal pregnant women,with gestational ages ranging from 13 weeks to 40 weeks. They found curvilinear relationships between the transverse diameter of the cerebellum and the gestational age $(\mathrm{R}=0.948 ; \mathrm{P}=0.001)$, the biparietal diameter $(\mathrm{R}=0.956 ; \mathrm{P}=0.0001)$, and the 


\section{Singh et al; Evaluation of Cestational age}

head circumference $(\mathrm{R}=0.969 ; \mathrm{P}=0.0001)$. A nomogram of cerebellar measurements estimating gestational age was generated. They concluded that throughout pregnancy normative cerebellar measurements allows for estimation of gestational age that is independent of the shape of fetal head. The result of this study is in concurrence with the above observation. In the present study there was good correlation between TCD and gestational age. $(\mathrm{R}=0.942, \mathrm{p}$ value $<0.001)$. Also good correlation was found between TCD and BPD $(\mathrm{R}=0.984, \mathrm{p}$ value $<0.001)$ and between TCD and HC $(\mathrm{R} 6=0.975$, p value $<0.001)$. In this study TCD normogram was established from ultrasonographically measured data which can be used for estimating the gestational age of fetus.

\section{Conclusion}

Transcerebellar diameter shows good correlation with gestational age in case of normal pregnancies and in case of IUGR and can be used as a independent growth parameter to predict the gestational age in normal and in intrauterine growth retarded pregnancies cases. Transcerebellar diameter to abdominal circumference ratio is fairly constant throughout gestation and thus it is a useful gestational age independent parameter.

\section{References}

1. D.C Dutta's: Text book of obstetrics, 7th edition 2004, 73-74.

2. Butt k, Fredericton NB ,Lim k : Determination of Gestational Age by Ultrasound, J Obstet Gynaecol Can 2014;36(2):171-181

3. Lerner JP. Fetal growth and well being. Obstet Gynecol. Clin N Am 2004; $31: 159-176$
4. Degani S. Fetal biometry: clinical, pathological, and technical considerations.Obstet Gynaecol Surv, 2001 Mar; 56:159-67.

5. Hadlock FP, Deter RL, Harrist RB, Park SK. Fetal abdominal circumference as a predictor of menstrual age.AJR Am J Roentgenol. 1982 Aug; 139(2):367- 70.

6. Hadlock FP, Deter RL, Harrist RB, Park SK. Fetal biparietal diameter: a critical reevaluation of the relation to menstrual age by means of real-time ultrasound. Ultrasound Med. 1982 Apr;1(3):97104.

7. Hadlock FP, Deter RL, Harrist RB, Park SK. Fetal head circumference: relation to menstrual age.AJR Am J Roentgenol. 1982 Apr; 138(4):649-53.

8. Deter RL, Harrist RB, Hadlock FP, Carpenter RJ. Fetal head and abdominal circumferences: II. A critical re-evaluation of the relationship to menstrual age. J Clin Ultrasound. 1982 Oct; 10(8):365-72.

9. Hadlock FP, Harrist RB, Deter RL, Park SK. Fetal femur length as a predictor of menstrual age: sonographically measured. AJR Am J Roentgenol.1982 May; 138 (5): 875-8.

10. A.S.M. Vinkesteijn, P.G.H. Mulder. Fetal transverse cerebellar diameter measurements in normal and reduced fetal growth. Ultrasound Obstet Gynecol 2000; 15: 47-51.

11. Davies MW., Swaminathan M., Betheras FR: Measurement of the transverse cerebellar diameter in preterm neonates and its use in assessment of gestational age. mwdavies@ozemail .com.au. Australas Radio 2001 Aug:45(3): 309-12

12. MS. Kramer, CV.Ananth, RW. Platt, et al. US Balck US White Disparities in foetal growth: physiological or pathological? Int J Epidemiol, Volume 35:1187-95, 2006

13. M.Swaminathan, MW. Davies, Davis PG, et al. Transverse cerebellar diameter on cranial ultrasound scan in pretermneonates in an Australian population. J. Paediatr. Child Health, Volume 35: 346-49, 1999.

14. Reece EA, Goldstein I, Pilu G, Hobbins JC. Fetal cerebellar growth unaffected by intrauterine growth retardation: a new parameter for prenatal diagnosis. Am J Obstet Gynecol 1987;157:632-38.

15. Goldstein I ,Reece EA, , Pilu G, Hobbins JC. Cerebellar measurements with ultrasonography in the evaluation of fetal growth and development. AM.J.Obstet. Gynecol 1987;156: 1065-1069.

Copyright: ( ) the author(s), publisher. Asian Journal of Medical Radiological Research is an Official Publication of "Society for Health Care \& Research Development". It is an open-access article distributed under the terms of the Creative Commons Attribution Non-Commercial License, which permits unrestricted non-commercial use, distribution, and reproduction in any medium, provided the original work is properly cited.

How to cite this article: Singh A, Thukral CL, Singh J, Gupta K, Pahwa S. Role of Transcerebellar Diameter Measurement with Ultrasonography in Evaluation of Gestational age in Normal and Growth Restricted Fetuses. Asian J. Med. Radiol. Res. 2018;6(2):08-11. DOI: dx.doi.org/10.21276/ajmrr.2018.6.2.3 